\title{
Textual factualization: \\ The phenomenology of assertive reformulation and presupposition during a speech event
}

\begin{abstract}
This work provides an operational framework to study the unfolding of new factual propositions out of originally suspended-factual (Narrog 2009, Tantucci 2015b) statements during a speech event. In particular, this model is centered on the dynamic relationship between cognitive control (i.e. Kan et al. 2013) and epistemic certainty. A speaker/writer's epistemic inclination towards the factuality of a proposition $\mathrm{P}$ occurs throughout a text, either in the form of the assertive reformulation of an originally suspended-factual proposition $\mathrm{P}$, or in the form of a presupposition trigger also turning $\mathrm{P}$ into a new factual statement. I refer to this phenomenon as textual factualization (TF) and I provide corpus data from the British National Corpus (BNC) to demonstrate it to be a frequent mechanism where an originally suspended-factual proposition [apparently $\mathrm{P}$ ] is subsequently factualized both in written and spoken texts. I argue that TF instantiates as a form of interference/misinformation effect (cf. Ecker et al. 2015) as it triggers the qualitative alteration of an event memory by partially overwriting an original memory trace: from [apparently $\mathrm{P}$ ] to [
\end{abstract}

Keywords: assertion; presupposition; evidentiality; factualization; cognitive control; misinformation effect 


\section{Introduction}

This paper proposes a new theoretical and operational model to investigate the encoding of factual propositions out of suspended-factual (cf. Tantucci 2015b) statements throughout a text or during a speech-event. Special focus is put on the relationship between cognitive control and epistemic certainty (cf. Kan et al. 2013, on cognitive control and Moore et al. 2009 on acti contingency).

More specifically, the present analysis looks at quantitative and qualitative corpus-data from the BNC to propose that phenomena of 'conflict monitoring' and perceptual/informational 'cognitive control' (cf. Norman \& Shallice, 1986; Botvinicket al. 2001; Miller \& Cohen 2001; Schlaghecken \& Martini 2012) not only instantiate at the perceptual level (i.e. inhibitory control necessary for overriding stimulus-driven behavioral responses), but also at the epistemic one (i.e. the epistemic inclination towards the factuality of a proposition in cases of uncertainty).

With this premise, I discuss how the pragmatics of presuppositions (cf. Stalnaker 1974, 1999, 2002; Cruse 2006; Huang 2007, 2011; Riemer 2010; Fetzer 2011) can trigger factual propositions either based on construals of immediate intersubjectivity (I-I) - i.e. profiling the awareness of a specific addressee - or extended intersubjectivity (E-I) - i.e. referring to a more general 3rd party (3rdP) in society (Tantucci 2013, 2015a, 2015c). In the latter case, presuppositions may prompt new factual propositions based on the epistemic assumption of $\bigcirc \mathrm{P}$ as an abstract interlocutor who is expected to potentially know or justify the factuality of $\mathrm{P}$ in a particular context. These points will constitute ieoretical prerequisite to propose that a $\mathrm{V}^{1}$ s epistemic inclination towards the factuality of a proposition P can be formally identified throughout a text, either in the overt form of an assertive reformulation of an originally suspended-factual P (cf. Narrog 2005: 679; Tantucci 2015a: 387 on undetermined/suspended factuality), or in the covert form of a presupposition trigger also turning $\mathrm{P}$ into a new factual meaning. I define this online process as textual factualization (TF) and demonstrate it to be surprisingly frequent in contexts where an originally suspended-fatual proposition [apparently P] - encoding interpersonal evidentiality (IE) (cf. Tantucci 2013, 2015a) is subsequently turned into a newly factual(-ized) proposition both in written and spoken texts.

This phenomenon can be preliminarily illustrated from the real example below:

\footnotetext{
${ }^{1}$ Speaker/writer.
} 
(1) Still, Rehm declared that Jack Kevorkian, who went to jail for killing terminally ill patients, "was before his time " an 'at " the country wasn't ready." But it's apparently ready now. The agenda is set.

COHA $^{2}$ - Giving our final days to God - 2015

Consider the last two propositions from (1) above: proposition P [it's apparently ready now] and $\mathrm{P}^{\prime}$ [The agenda is set]. While the factuality o $\mathrm{o}^{\circ}$ mer is 'suspended', as it can be epistemically defeased or questioned, the latter co

(1) a. The country is apparently ready now, though this is yet to be confirmedlyet this is not for sure.

b. The agenda is set, *though this is yet to be confirmed $/ *$ yet this is not for sure.

The online phenomenology of the shift from $\mathrm{P}$ to $\mathrm{P}^{\prime}$ is what in this paper will be addressed as textual factualization (TF), namely, the re-positing of an originally suspended-factual proposition $\mathrm{P}$ in the new form of a factual proposition P'. This is illustrated in the shift from (1a) to (1b) above, as the statement [the agenda is set] entails (つ) that [the country is apparently ready now]. Throughout a speech-event, TF instantiates as a type of interference effect (also defined as misinformation effect), viz. the qualitative alteration of an event memory (cf. Ayers \& Reder 1998; Paz-Alonso \& Goodman 2008; Frenda et al. 2011; Ecker et al. 2015) by either partially overwriting the original memory trace (i.e. Loftus et al. 1978; Belli et al. 1994) or blocking the original memory trace at retrieval (Bowers \& Bekerian 1984; Loftus 2005). In this study, phenomena of TF will be to be an instance of the former: from [apparently $\mathrm{P}$ ] to [appenty $\mathrm{P}$ ].

This paper is structured as follows: D tion 2 first briefly introduces the reader to the framework of anistemic control cycle ECC and proposes a new intersubjective configuration of the ECC model. secion 3 is centered on the notion of textual factualization (TF) and its relationship with assertions and presuppositions. Concerning the latter, in 3.1 I discuss the relationship between

\footnotetext{
${ }^{2}$ Corpus of Historical American English (last accessed 16/03/2016) (cf. Davis 2010).

${ }^{3}$ The present study theoretically draws from Narrog's $(2005,2009)$ and Tantucci's $(2015$, forthcoming) understanding of factuality, intended as the domain of un-modalized expressions. From this perspective, factuality entails certainty:

The Alps are in Italy, *but maybe this is not true.

The Alps may be in Italy, but maybe this is not true.
}

This is also captured in Capone (2001) where it is posited that if a speaker uses an unqualified utterance (an utterance without a modal expression), $\mathrm{s} / \mathrm{he}$ is committed to its truth, since $\mathrm{s} / \mathrm{he}$ is obeying the quality maxim. 
presuppositions and immediate-intersubjective/extended-intersubjective (I-I/E-I) awareness. Section

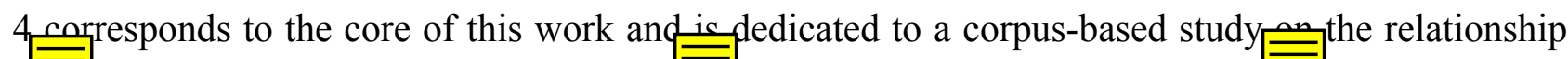
beiween evidential reasoning and online phenomena of T⿰ More specifically, in 4.1 I first show the suspended-factual status of indirect evidentials (cf. Wilıuı 1988; Aikhenvald 2004; Tantucci 2013). This brief discussion serves as a theoretical prerequisite to the final analysis in sections 4.2 and 4.3 which provides the results of a corpus survey focusing on phenomena such as the one exemplified in (1a-b), viz. cases of TF of a proposition $\mathrm{P}^{\prime}$ occurring in ${ }^{-}$ame text where an ginally suspended-factual evidential proposition [apparently P] first appeared.

\section{The (intersubjective) epistemic control cycle (I)ECC}

In cognitive science, cognitive control (also known as executive functions or supervisory attentional system) stands for a range a of cognitive mechanisms - including attentional control, inhibitory control, working memory, and cognitive flexibility, as well as reasoning, problem solving and planning selecting - aimed at monitoring behaviors that facilitate the attainment of chosen goals (i.e. Diamond 2013; Kan et al. 2015).

In Cognitive linguistics, Langacker $(2008,2009)$ adopts the notion of control cycle to refer to an embodied dynamic process unfolding at various levels: physical, perceptual, mental or social. For example, in the physical domain feeling hungry and noticing an apple may form a state of tension, which can be resolved by grabbing it and eating it. Most crucially, the control cycle also occurs at the epistemic level: we learn and acquire new ideas and information, assess them for their possible validity before we resolve this tension of uncertainty by either believing them to be true or false. Simply put, the tension of uncertainty between a subject and the information s/he takes into account is generally to be resolved in some way. $\mathrm{S} /$ he is generally inclined to decide whether to believe that a proposition $\mathrm{P}$ is true or false so that $\mathrm{s} /$ he can 'exert epistemic control' over that particular piece of knowledge. On a subjective level, the epistemic control cycle (ECC) model is compatible with most influential studies in cognitive psychology concerning 'conflict monitoring theory' and perceptual/informational 'cognitive control' (cf. Norman \& Shallice, 1986; Botvinicket al. 2001; Miller \& Cohen 2001; Schlaghecken \& Martini 2012). Yet, what has Langacker not problematized is the most likely intersection between the ECC and construals of intersubjectivity. Despite the variety of approaches in the recent literature, intersubjectivity is generally intended as the awareness of feelings and epistemic standpoints of other individuals (generally interlocutors) which may differ from our own during a speech event (cf. Nuyts 2001, 2012; Verhagen 2005; 
Traugott 2010, 2012; Tantucci 2013; see also Premack and Woodruff 1978; Goldman 2006; Nichols \& Stich, 2003; Tomasello 2009 on the more general notion of theory of mind and mindreading in cognitive psychology).

With this in mind, if we transpose the ECC onto the intersubjective domain, we will then have the embodied schema of an agent A exerting a form of control over a target $\mathrm{T}$ also taking into account a beneficiary (either singular or plural) B. In this perspective, A will act over a target $\mathrm{T}$ in order to provide a new entity to a shared dominion D. In this sense, the new acquisition made by A is determined by the intersubjective awareness of him/herself plus the other persona B. Drawing on Langacker's model of the subjective construing of the control cycle, I schematically provide below the same process of acquisition with the new addition of a symbolic beneficiary B:

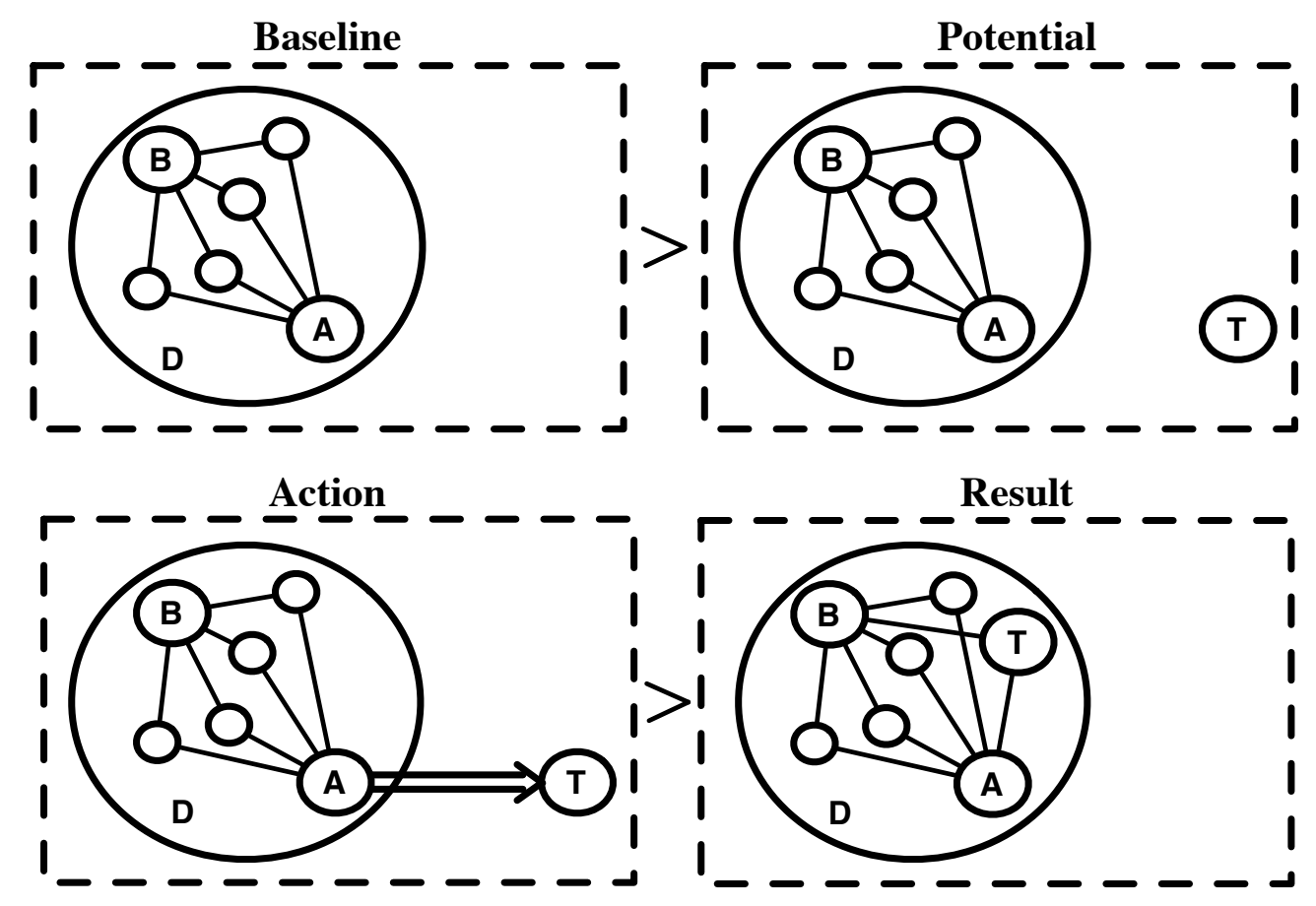

Figure 1.

The intersubjective control cycle (ICC)

Figure 1 represents the four phases of the $\mathrm{CC}$ when it is construed intersubjectively: respectively baseline, potential, action and result. This work will be centered on the shift from action to result, as the incorporation of $\mathrm{T}$ does not simply involve one single actor $\mathrm{A}$ and his/her own dominion, but also a beneficiary $\mathrm{B}$ who is expected to share control over the new entity incorporated by $\mathrm{A}^{4}$.

\footnotetext{
${ }^{4}$ This physical process occurs very frequently in people's life. Imagine for instance a mother seeing a cake exposed in a bakery shop, buying it and then enjoying it together with her children.
} 
During a speech event, A and B are to be intended respectively as a speaker/writer SP/W and an addressee/reader $\mathrm{AD} / \mathrm{R}$, the target $\mathrm{T}$ corresponds to a proposition $\mathrm{P}$, while $\mathrm{D}$ then corresponds to their shared epistemic dominion, viz. their common ground CG (i.e. Clark \& Brennan 1991; Koschmann 2003). In fact, other than being always restricted to our subjective set of beliefs, an epistemic process of factualization (cf. Tantucci 2015b) can also occur intersubjectively - viz. for the benefit of an addressee - along what I define here as the intersubjective epistemic control cycle (IECC). In this case, the progressive or abrupt acquisition of a new factual proposition $\mathrm{P}$ is not autonomous (as for the ECC), but rather overtly or covertly prompted by a SP/W in the direction of an AD/R. Crucially, the shift from the 'action' to the 'result' stage pragmatically maps the instantiation of a constative speech act during a speech event:

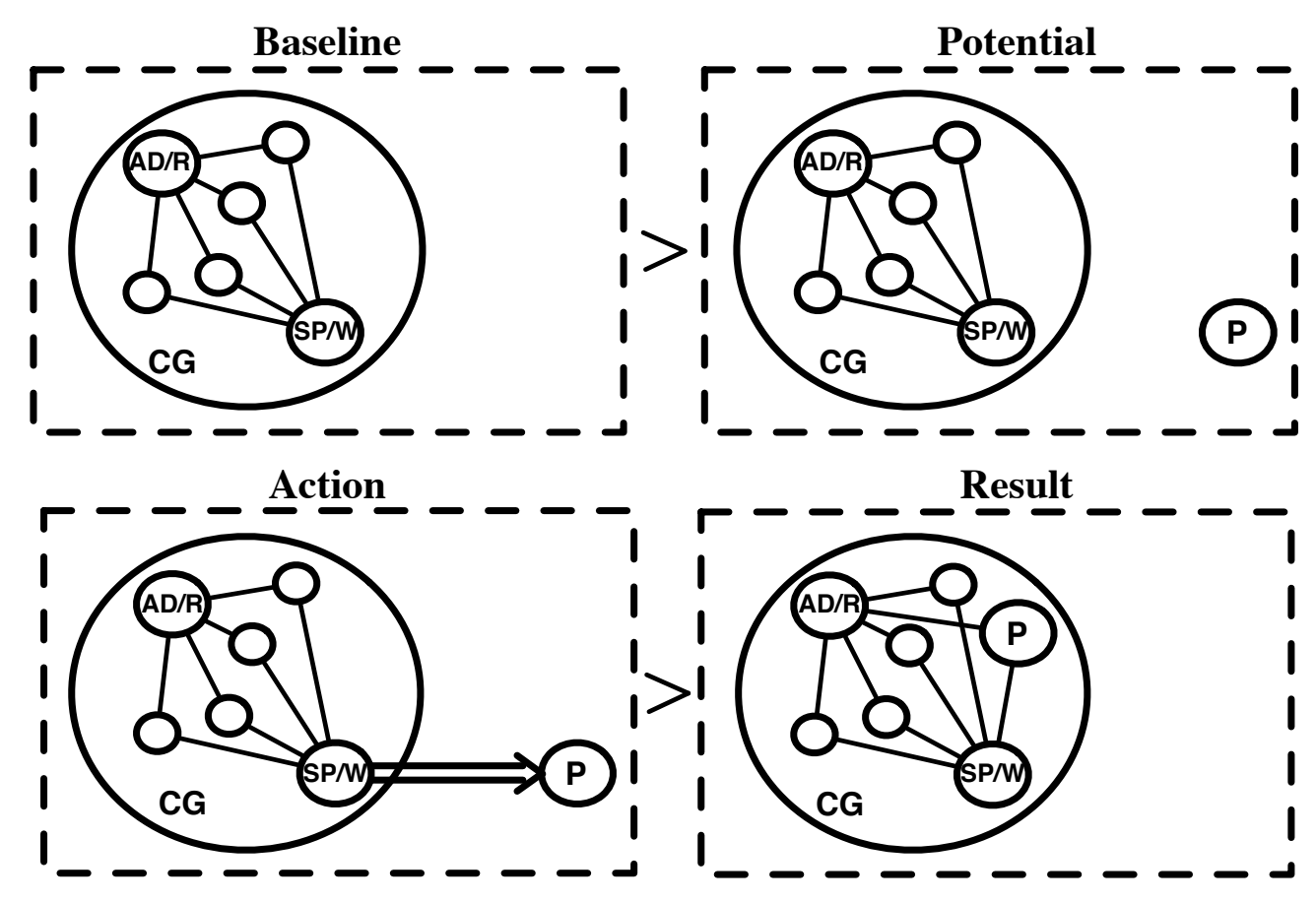

Figure 2.

The intersubjective epistemic control cycle (IECC)

\section{Overt and covert functions of textual factualization (TF)}

During a speech-event a new proposition $\mathrm{P}$ can be encoded as a new factual element becoming part of the interlocutors' shared knowledge. From a conceptual point of view, this phenomenon can be intuitively defined as textual factualization (TF). Phenomena of textual 
factualization, as we shall see, can be encoded overtly or covertly. The former mostly occurs when a $\mathrm{SP} / \mathrm{W}$ communicates assertively a proposition to an $\mathrm{AD} / \mathrm{R}$ :

(2) I have to tell you, there's not much left over.

BNC H46 1068

Example (2) is quite straightforward and intuitive: a new proposition $\mathrm{P}$ is communicated assertively by $\mathrm{SP} / \mathrm{W}$ to $\mathrm{AD} / \mathrm{R}$. On a more conceptual level, a new piece of information is cooperatively added to the common ground that includes all knowledge shared by $\mathrm{SP} / \mathrm{W}$ and $\mathrm{AD} / \mathrm{R}$. Assertions made during a speech-event continuously establish dynamic relations between the interlocutors and all knowledge they both accept to be factual, as they contribute to the online creation of the common ground (cf. Kecskes \& Zhang 2009, 2013). A proposition is posited as a fact every time a SP/W does not overtly mark a proposition modally or evidentially, as in both cases s/he would specifically encode a lack of personal commitment towards P (cf. Faller 2002; Narrog 2005, 2009; Tantucci in press). An assertive speech act is then by definition a form of overt textual factualization (TF) where SP/W adds a piece of new information $\mathrm{P}$ to the common ground s/he shares with AD/R (cf. Searle 1969; Strawson 1973; Sbisà 2009; Jary 2010 on assertivity). In this sense, I treat assertions as 'co-act proposals' (Reich 2012). That is, rather than neutrally providing information, SP/W communicates a piece of information to $\mathrm{AD} / \mathrm{R}$ with the aim of affecting $\mathrm{AD} / \mathrm{R}$ 's belief system in accordance with his/her own one.

Along an ideal IECC, assertions correspond to the so-called 'action' stage where a new proposition is factual(-ized) with respect to $\mathrm{SP} / \mathrm{W}$ and $\mathrm{AD} / \mathrm{R}$ 's common ground $\mathrm{CG}$. This is exemplified in the diagram below:

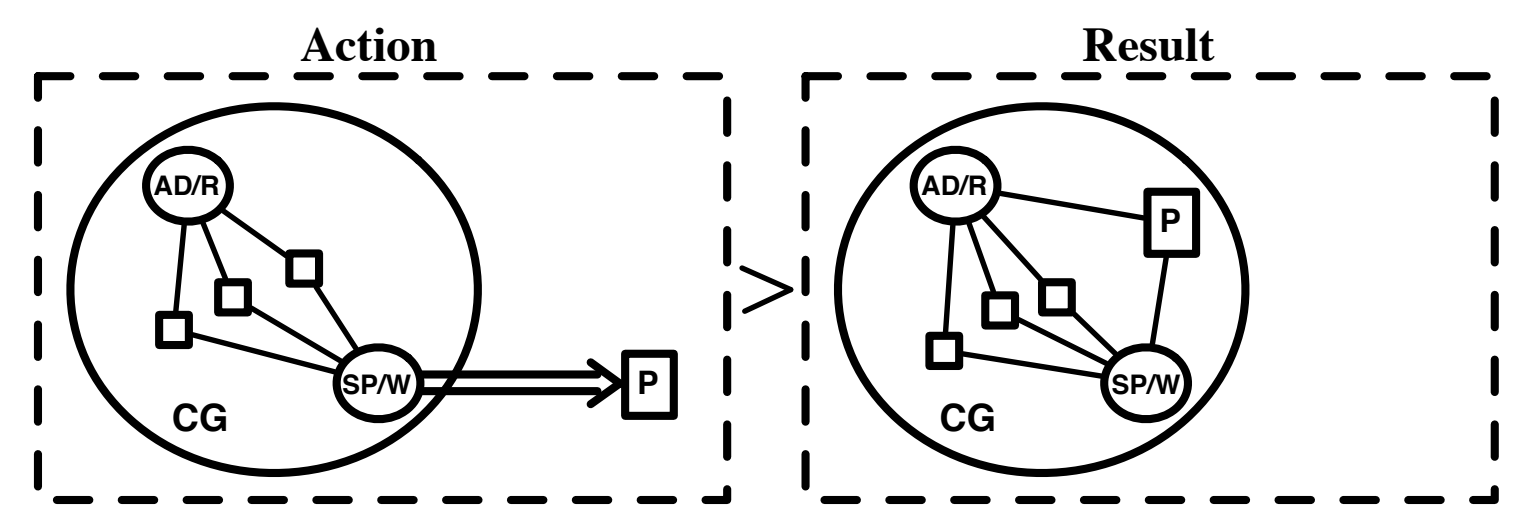

Figure 3.

Assertion along the IECC 
While the diagram above accounts for overt kinds of $\mathrm{TF}$, the latter often occur textually also in a more covert fashion, through presupposition ( $>>)$. A presupposition is an implicit assumption about the world or background belief relating to an utterance whose truth is taken for granted in discourse (Stalnaker 1974, 1999, 2002). More importantly, a presupposition corresponds to a proposition the factuality of which is taken for granted by the producer of an utterance and which must be known and taken account of for the utterance to make sense to an interpreter (cf. Cruse 2006: 138; Fetzer 2011: 32). Consider the example below:

(3) It was/wasn't the porter who called a taxi for John.

>>5 (I know you know that) someone called a taxi for John.

(Huang 2011: 402-403)

In the case above, $\mathrm{SP} / \mathrm{W}$ does not simply make a negative assertion $\mathrm{P}$, but also presupposes a proposition Q which is expected to be already known by AD/R (cf. Atlas \& Levinson 1981 on itclefts and presupposition). In other words, every assertion that includes a presupposition always conveys a piece of new information $\mathrm{P}[\text { It was/wasn't the porter who called a taxi for John }]^{6}$, together with a piece of old information Q [Someone called a taxi for John].

Presuppositions can be identified constructionally, as they are formally encoded through presupposition triggers (cf. Stalnaker 1974, 1999, 2002; Delogu 2009; Huang 2011; Fetzer 2011). The latter correspond to a set of constructional instantiations of a presupposed element Q: i.e. they can occur in the form of temporal clauses, cleft sentences, counterfactual conditionals and other constructions. In (3) above the presupposition is pragmatically triggered by the pronoun who which functions as the head of the cleft-sentence construction [who called a taxi for John]. Presuppositions correspond to the formal instantiation of a pragmatic strategy, and for this reason, they crucially differ from entailments $(\supset)$, which are based on semantic and logical relations. Similarly, presuppositions also need to be distinguished from conversational implicatures $(\Rightarrow)$, as the latter regard some aspects of what is meant in an utterance without being formally part of what is said (i.e. Levinson 2000; Horn 2006: 36-39; Cruise 2006: 37). For the moment, we will be more

5 " >>" is an operator expressing it is presupposed that.

${ }^{6}$ As this paper will be focused on the semantic-pragmatic relationship between propositions, for the readers' clarity, I will enclose them within square brackets. 
interested in the pragmatics of presuppositions and their relationship with intersubjectivity. Nonetheless, entailments and implicatures will also constitute an important part of the case study in section 4.

\subsection{Immediate and extended construing of presuppositions}

One fundamental point that needs to be remembered for the purposes of the following analysis, is that a presupposed piece of old information Q can be construed and referred to in various ways. It can be anaphoric - viz. referring back textually to a proposition already introduced throughout the discourse - or it can refer more broadly to the common ground (cf. Clark \& Brennan 1991; Koschmann 2003), elsewhere also defined as mutual knowledge (cf. Clark \& Carlson 1981; Clark \& Marshall 1981).

The common ground indicates aspects of knowledge that SP/W and AD/R would assume to be shared and, therefore, do not need to be spelt out. It "includes what can be perceived in the immediate context, together with knowledge of the language, general world knowledge, shared attitudes, and so on" (cf. Cruse 2006: 28). In most cases, example (3) in section 3 can be intended as an instance of anaphoric presupposition, as SP/W refers to $Q$ as a textual element of a specific ongoing conversation. On the other hand, "not only linguistic context interacts with presuppositions" (Piwek \& Krahmer 2000: 85) as people often deal with occurrences where a presupposed proposition $\mathrm{Q}$ has not been necessarily expressed textually throughout the speechevent, but more broadly refers $\mathrm{SP} / \mathrm{W}$ and $\mathrm{AD} / \mathrm{R}$ 's mutual knowledge as such. See the following spoken example from the British National Corpus (BNC):

$$
\begin{aligned}
& \text { A: The gloves are good. } \\
& \text { B: Yeah? } \\
& \text { >> (I know you know that) there is a pair of gloves I am using. }
\end{aligned}
$$

BNC KCL 1552

In (4) above, the definite article the functions as a presupposition trigger, as it anaphorically refers to an element of the discourse which is assumed to be known both by SP/W and AD/R: There is a pair of gloves you know I am using (cf. Van der Sandt 1992; Geurts 1999 on the correspondence of anaphoras and presuppositions; see also Von Heusinger 2013 on definiteness). However, different from (3), in this latter case the presupposition Q is not anaphorically attached to a (close) textual 
element of the discourse. In other words, the gloves are here mentioned the first time during the speech-event. The employment of the definite article the is due to a SP/W's reference to a piece of knowledge s/he shares with $\mathrm{AD} / \mathrm{R}$. It follows that, to various degrees, presuppositions referring to the common ground are the result of a SP/W's epistemic assumption regarding AD/R's knowledge. As this is a most crucial aspect of presuppositions and their pragmatic employment, it is important to stress that:

Presuppositions are not only textual, but can also involve embedded assumptions.

Most interestingly, assumptions concerning the speech participants' common ground can be very straightforward and self-evident - as in the case of (4) above - but can also be the result of more abstract and inferential generalizations about $\mathrm{AD} / \mathrm{R}$ 's knowledge. Consider the spoken monologue below form the BNC where SP/W presupposes a proposition $\mathrm{Q}$ for the first time in a text:

\section{[...] and we have finally got erm to the stage in Chinese history where Mao Tse-tung's role becomes crucially important.}

>> (I know you know that) there is a stage in Chinese history where Mao Tse-tung's role becomes crucially important.

Concerning the utterance in (5) above, there is a first question that needs to be asked: does the professor lecturing about Chinese history know for sure that all his/her student are aware of a particular stage in history where Mao Tse-tung's role becomes crucially important? Evidently, the answer is no, s/he does not know that with certainty. S/he rather apparently assumes that all the students in the class - or at least most of them - already have some cultural and historical background about the Cultural Revolution and Mao Ze Dong7's important role in Chinese history. There is then a second question that naturally arises: as the professor presumably does not know most of his/her students, how can s/he delimitate the boundaries of the common ground including his/herself and his/her students' knowledge? To put it differently, how can s/he assume what and how much the students already knew before his/her lecture?

\footnotetext{
${ }^{7}$ Transcribed in Mandarin pinyin.
} 
To answer this question, I adopt a theoretical and methodological framework proposed in Tantucci $(2013,2015 \mathrm{c})$ tackling the gradient relationship between immediate (I-I) and extended intersubjectivity (E-I). The former (I-I) needs to be intended as the intersubjective dimension where a $\mathrm{SP} / \mathrm{W}$ profiles his/her awareness of a specific $\mathrm{AD} / \mathrm{R}$, generally present during the here-and-now of the discourse. The latter (E-I) has to do with a more extended construal of intersubjective awareness, taking into account a general 3rd party (3rdP) who can be either singular or plural, specific or general. 3rdP is assumed as an external interlocutor who could potentially join the ongoing speech event and who is expected to confirm SP/W's epistemic or emotional stance towards P.

To explain, in the case of (5) above, the professor's apparent assumption about the student's knowledge is the result of an E-I form of awareness whereby 3rdP becomes a crucial element of the utterance. The proposition [The stage in Chinese history where Mao Tse-tung's role becomes crucially important] is in fact a piece of knowledge that 3rdP is assumed to be aware of and which s/he could potentially confirm (cf. Abbott 2000 about information status of presuppositional triggers). 3rdP can be constituted by all those people who actually discussed about that stage in Chinese history and the ones who - in one way or another - came to know about it.

As Stalnaker crucially remarks, "what is most distinctive about this propositional attitude is that it is a social or public attitude: one presupposes that [Q] only if one presupposes that others presuppose it as well" (Stalnaker 2002: 701). For this reason, I define the utterance in (5) as a form of extended-intersubjective (E-I) presupposition, which can be distinguished - along a conceptual continuum - from more AD/R's oriented immediate-intersubjective (I-I) presuppositions (the latter are more prototypically exemplified in examples 3 and 4). The expected accommodation of SP/W's presupposition is also confirmed by that fact that "conversation entails low levels of justification about what speakers ought to share, [making it] possible for an assertion to sound appropriate even if there is no specific relevant element in the propositional context to satisfy that specific statement" (cf. Domaneschi 2011: 3828).

Crucially, not necessarily does SP/W presume to know that $\mathrm{AD} / \mathrm{R}$ knows what $\mathrm{s} / \mathrm{he}$ is presupposing (cf. Simons et al. 2010; Tonhauser 2012 on the notion of at-issueness). In (5) and in similar cases of informative presuppositions (Karttunnen 1974), SP/W rather adopts an extendedintersubjective (E-I) stance whereby it is a general 3rdP who is rather assumed to be aware of what $\mathrm{SP} / \mathrm{W}$ is presupposing. As a result, the at-issueness of what $\mathrm{SP} / \mathrm{W}$ is communicating is inherently based on an E-I type of cognitive construal. It is precisely this assumed social meaning what allows $\mathrm{SP} / \mathrm{W}$ to posit a new piece of information in the form of a presupposition. Concerning this point, 
Allan (2013: 305) also emphasizes that "the notion of common ground necessitates a community $[\ldots]$ that observes social norms such as that $[\mathrm{S} / \mathrm{PW}]$ and $[\mathrm{AD} / \mathrm{R}]$ are mutually aware that, normally, their interlocutor is an intelligent and aware being".

In fact, as E-I presuppositions are based on knowledge shared with an assumed 3rdP, they can thus be made in presence of people completely unknown to SP/W. On the other hand, I-I presuppositions are comparatively more $\mathrm{AD} / \mathrm{R}$ specific and refer to pieces of knowledge which directly regard SP/W and $\mathrm{AD} / \mathrm{R}$ 's common ground. Additionally, we equally need to bear in mind that all E-I presuppositions are first based on SP/W's assumption of what 3rdP know(s), and only in a second stage, co-operatively encoded as part of $\mathrm{AD} / \mathrm{R}$ 's knowledge structure. In this sense, on $\mathrm{AD} /$ R's behalf to "accept a proposition is to treat it as true for some reason. One ignores, at least temporarily, and perhaps in a limited context, the possibility that is false. Belief is the most basic acceptance concept.” (Stalnaker 2002: 716).

\subsection{On the phenomenology of E-I presuppositions}

In figure 4 below I provide a representation of the conceptual and pragmatic phenomenology of E-I presuppositions:

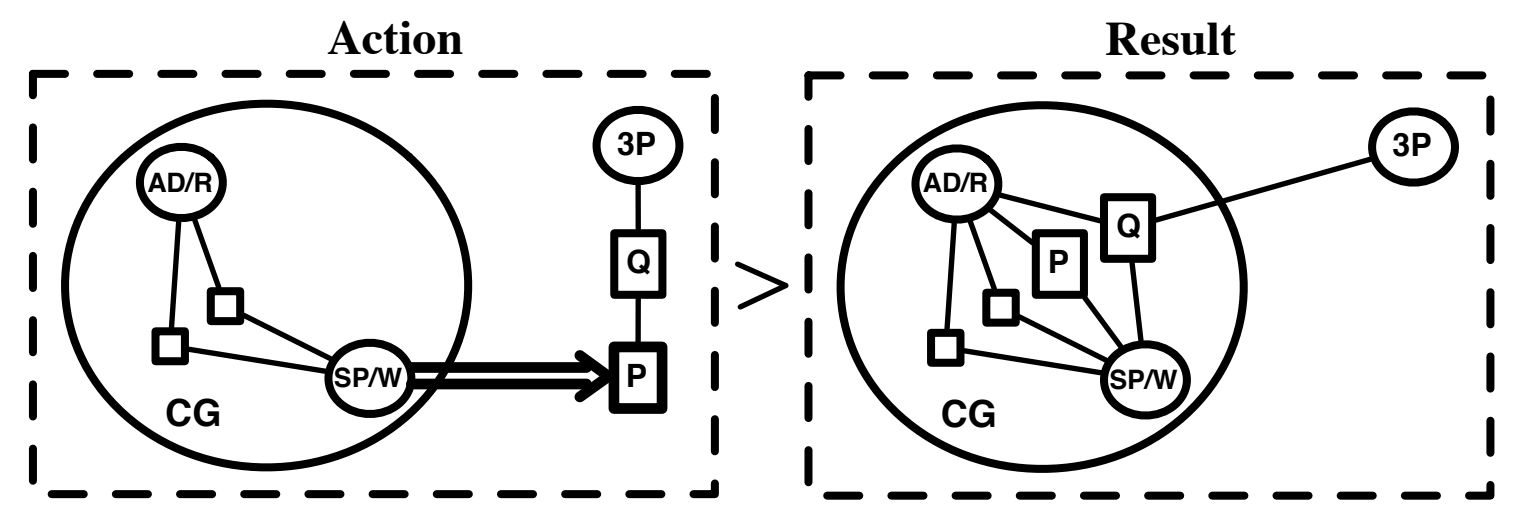

Figure 4.

E-I presuppositions along the IECC 8

In the action stage above - the one where an assertive speech act occurs - SP/W textually adds a piece of new information $\mathrm{P}$ to the common ground $(\mathrm{CG}) \mathrm{s} /$ he shares with $\mathrm{AD} / \mathrm{R}$ : [we have finally got to the stage in Chinese history where Mao Tse-tung's role becomes crucially important]. In addition to that, $\mathrm{s} /$ he attaches to $\mathrm{P}$ a proposition $\mathrm{Q}$, pragmatically encoded as old information: [there

\footnotetext{
${ }^{8}$ For reasons of space and readability, $3 \mathrm{rdP}$ is labeled as $3 \mathrm{P}$ in the figure.
} 
is a stage in Chinese history where Mao Tse-tung's role becomes crucially important]. As I emphasized, Q in (4) is neither anaphoric of a previous element in the discourse, nor it corresponds to a information being part of SP/W and AD/R's CG. Rather, Q in this case is the result of what SP/ $\mathrm{W}$ assumes about 3rdP's knowledge and thus it can be plausibly presented as a piece of old information to $\mathrm{AD} / \mathrm{R}$. This is clear in the action stage from figure 4 above, where $\mathrm{Q}$ is not part of the CG yet, but rather externally connected to $3 \mathrm{rdP}^{9}$.

From the diagram, we can observe an overt form of $\mathrm{TF}$, which corresponds to the acquisition of $\mathrm{P}$ as a new piece of information, added in the form of an assertion to CG. In addition to that, we can also observe a covert form of $\mathrm{TF}$, which regards the abrupt textual identification of $\mathrm{Q}$ as a piece of old information also becoming part of CG. This second phenomenon is conceptually and pragmatically sudden and subtle, as what is in profile in SP/W's utterance, is a piece of new information $\mathrm{P}$, while $\mathrm{Q}$ is encoded as a proposition the factuality of which is so obvious, it does not need to be spelled out assertively. On both a conceptual and pragmatic level, the effect of E-I presuppositions is always the textual addition of two propositions to CG: P (asserted) and Q (presupposed). As we will see in sections 4.2 and 4.3, E-I presuppositions are often employed with the effect of turning a suspended-factual piece of information into a new factual proposition throughout a text.

\section{Textual Factualization (TF): A qualitative and quantitative analysis}

In the next sections I analyze corpus data regarding intersubjective phenomena of overt and covert textual factualization (TF). More specifically, I look at instances in which a proposition $\mathrm{P}$ is first introduced in a discourse as an interpersonal evidential (IE) construction [apparently, P]. IE constructions such as [apparently, P] mark $\mathrm{P}$ as a piece of knowledge SP/W shares with a general 3rdP in society (cf. Tantucci 2013). What will emerge from this survey will be that the latter is often turned into a factual proposition throughout a text. Simply put, what is first introduced in a text as a suspended-factual proposition $\mathrm{P}$, is often subsequently turned into a new factual proposition Q (or Q').

One fundamental precondition for this analysis, is the assumption that IE, and indirect evidential constructions in general, do not mark a proposition $\mathrm{P}$ as a factual statement, but rather

\footnotetext{
${ }^{9}$ Represented as $3 \mathrm{P}$ in the diagram.
} 
convey suspended-factuality (cf. Tantucci $2015 \mathrm{~b}$ for a detailed account of factual gradience) or undetermined factuality (Narrog 2005, 2009). I briefly illustrate this point in the next subsection.

\subsection{On the relationship between factuality and indirect evidentials}

As is known, evidentiality is defined as the scope referring to the source of information of a statement (i.e. Chafe \& Nichols 1986; Willett 1988; Aikhenvald 2004) or more broadly as acquired knowledge (Tantucci 2013) or mode of knowing (Cornillie 2009). Traditionally, evidentiality is described in the literature as a dual domain. Direct evidentials mark the SP/W's direct experiencing of the fact described, and they can be semantically paraphrased as I saw that P. Conversely, indirect evidentials generally indicate a source of information other than a SP/W's direct involvement in the event: this often corresponds to second or third-hand information, to an inference from some visible or approachable results or, more generally to a form of shared knowledge and can be roughly paraphrased as from what I heard/apparently, P.

Narrog (2009) points out that factuality may come into play in the distinction between direct and indirect evidentiality. Consider the three statements below:

(6) Apparently, the pilot sped up, but we landed earlier then expected.

(7) Scientists are allegedly the most logical of human beings.

(8) Elvis has left the building, I've seen it.

(Narrog 2009: 10)

In Narrog's view, apparently in (6) and allegedy in (7), are adverbials of indirect evidentiality as they relativise their factuality in relation to some external evidence. More specifically, they are interpersonal evidentials (IE), viz. markers of 'shared knowledge' (Tantucci 2013). In contrast, the direct evidential strategy I've seen it in (8) does not affect the factual status of the proposition. Simply put, Narrog intends direct evidentiality as a factually marked proposition, whereas the factuality of indirect evidentials remains undetermined (cf. Tantucci in press for a more specific discussion of this issue). Below I provide a test to show the suspended-factual character of indirect evidentials: 
(9) A: Apparently, the pilot sped up.

B: Is that true?

A'?: Yes.

A": I don't know, apparently.

(10) A: Scientists are allegedly the most logical of human beings.

B: Is that true?

A'?: Yes.

A": I don't know, allegedly (they are).

(11) A: Elvis has left the building, I've seen it.

B: Is that true?

A': Yes.

A"*: I don't know, I've seen it.

On a semantic-pragmatic level, both (9) and (10) are not logically consistent as, once s/he is SP/W questioned about the factuality of $\mathrm{P}, \mathrm{s} /$ he then replies affirmatively with a yes. That is due to the entailed 'undetermined' or suspended-factuality of any form indirect evidential stance: indirect evidential constructions do not strictly mark a proposition as a fact, but rather as a statement that may be 'potentially confirmed' (cf. Faller 2002 on presentativity). Conversely, to reply with I don't know - hence literally suspending the factuality of $\mathrm{P}$ - would be pragmatically consistent as it would confirm SP/W's original lack of personal commitment towards P. Quite differently, the direct evidential stance adopted in (11) allows - or rather compels - SP/W to reply assertively with a yes. In fact, on A's behalf, to answer with I don't know - hence suspending the factuality of $\mathrm{P}-$ after the direct evidential I've seen it, would here sound logically inconsistent.

To conclude, what comes to light after these points, is that indirect evidentials IE constructions do not mark events as factual, as they entail suspended-factuality. They are employed to present a piece of information to $\mathrm{AD} / \mathrm{H}$ without any subjective commitment to the factuality of $\mathrm{P}$.

\subsection{Textual factualization (TF): A method of enquiry}


Before discussing the results of the present corpus-survey, it is first necessary to operationalise the present approach to TF on an empirical level so that we can rely on a formal framework of analysis. This can be done by clarifying three points:

a. What kind of TF propositions are of interest in the present study?

b. How can they be formally identified throughout a text?

c. What type of suspended-factual propositions $\mathrm{P}$ will be analysed in this survey?

To answer question (a), I focus on TF propositions instantiating either in the form of an assertive reformulation $\mathrm{P}$ ' from a previous suspended-factual proposition $\mathrm{P}$ or the presupposition $\mathrm{Q}$ referring back to a suspended-factual proposition P. In other words, I am interested in TF when it occurs overtly in the form of a new assertion P', or covertly, in the form of a presupposition Q. As can be imagined, from a methodological point of view, it is necessary to start from a suspended-factual presupposition type $\mathrm{P}$ and then look at subsequent phenomena of TF (when they occur) in the form of a new assertion P' or a presupposition Q throughout a text.

On a formal level - and here I answer question (b) - assertive (or overt) TF is easy to identify, as it allows SP/W to re-posit a suspended-factual proposition $\mathrm{P}$ in the form of a new assertion P'. See example (12) from the BNC:

(12) September was nine hundred and seventy six. [...] So it appears that it's increased. [...]

The original old ones, we're still on those, but it's still going up again.

BNC JTC 919

P: $\quad$ it appears that it's increased.

P': $\quad$ it's still going up again.

Q: $\quad$ it's increased.

According to Grice's maxims of manner and quantity (1976) SP/W is expected to avoid unnecessary prolixity (wordiness, repetition of the same ideas) and not to make a contribution more informative than required ${ }^{10}$. Not surprisingly, it is very rare to find the same proposition repeated

\footnotetext{
${ }^{10}$ Important to realize that, as emphasized by Grice, a violation of the maxim may occur with the aim of generating implicatures.
} 
twice in a text (first posited as suspended-factual P, and immediately after newly worded as factual P'). From this it follows that when we encounter an instance of assertive (or overt) TF, the textual relationship between $\mathrm{P}$ and $\mathrm{P}^{\prime}$ is generally based on entailment:

$$
\mathrm{P}^{\prime} \supset \mathrm{Q}=(\mathrm{TF}) \mathrm{P}
$$

To spell this out, a new proposition P' semantically entails Q which corresponds to a TF (textually factualized) version of the originally suspended-factual proposition $\mathrm{P}$. This in fact correlates with the textual phenomenology of (12), as the new factual proposition P' [it's still going up again] semantically entails (つ) that the originally suspended-factual proposition P [it appears that it's increased] is now turned into a factual proposition Q [it's increased] which now has become part of $\mathrm{SP} / \mathrm{W}$ and $\mathrm{AD} / \mathrm{R}$ 's common ground. In this sense, the reason why the relationship between $\mathrm{Q}$ and $\mathrm{P}$ is expressed as $\mathrm{Q}=(\mathrm{TF}) \mathrm{P}$ is namely because the entailed proposition $\mathrm{Q}$ is semantically equal $(=)$ to a TF version of the original $\mathrm{P}^{11}$. The ultimate effect of this whole process is then the textual reconfiguration of a suspended-factual proposition $\mathrm{P}$ [it appears that it's increased] into a factualized proposition $\mathrm{Q}=(\mathrm{TF}) \mathrm{P}[$ it's increased $]$.

As I emphasize above, SP/W predictably is not to use the same wording of $\mathrm{P}$ when s/he adopts a new assertive stance in P'. Yet, what comes to light in (12) is that P' now entails a new 'factualized' understanding Q of the original proposition P. This is easily verified, as the logical conjunction $(\wedge)$ between $\mathrm{P}^{\prime}[$ it's still going up again] and -Q [it is not increased] would lead $(\vdash)$ to contradiction or inconsistency $(\perp)$ :

a. $P^{\prime} \wedge-Q \vdash \perp$

* [it's still going up again] and [it is not increased]

A similar configuration of assertive (or overt) TF is based on implicature $(\Rightarrow)$, whereby P' conveys $\mathrm{Q}$ as a result of a pragmatic strategy (like presuppositions they are pragmatically defeasible) rather than being based on a logical relationship. See the example below from the BNC:

\footnotetext{
${ }^{11}$ As the here provided are all real examples, the semantic (and textually determined) equivalence between P' and Q may not be absolute on a logical level (it is almost impossible in most real speech events). In fact, the present account is aimed at capturing a conceptual tendency towards factuality, which cannot be assimilated to the idea of absolute logic equivalence.
} 

successful in worldly pursuits [...] many of them are highly successful careerists in professional and business life.

P: $\quad$ such evangelicals seem to be successful in worldly pursuits

P': $\quad$ many of them are successful careerists in professional and business life

Q: $\quad$ such evangelicals are successful in worldly pursuits

The parenthetical as it seems and similar pragmatic strategies, such as [seems to be $\mathrm{P}$ ] are often employed as a marker of interpersonal evidentiality (IE), as they construe a form of shared knowledge linking SP/W with an assumed 3rdP also aware of a proposition P (cf. Tantucci 2013, 2015c; see also Norrick 2000 on the gradient relationship between re-telling and shared knowledge within a community). However, it is shown in section 4.1 that IE and other indirect evidentials entail suspended-factuality, as they do not encode SP/W's subjective commitment towards the factuality of P. For this reason, we need to bear in mind that the IE proposition P [such evangelicals seem to be successful in worldly pursuits] in (15) above is to be considered suspended-factual.

Slightly different from (12), in the case of (15) above, the TF relationship between the newly asserted $\mathrm{P}^{\prime}$ and $\mathrm{Q}$ is not established logically through entailment ( $\left.\mathrm{P}^{\prime} \supset \mathrm{Q}\right)$, but rather pragmatically through conversational implicature ( $\left.\mathrm{P}^{\prime} \Rightarrow \mathrm{Q}\right)$. More specifically, the factual assertion $\mathrm{P}^{\prime}$ [ many of them are successful careerists in professional and business life] refers back to the IE proposition $\mathrm{P}$ [such evangelicals seem to be successful in worldly pursuits]. The former pragmatically implies $\Leftrightarrow) \mathrm{Q}$ [such evangelicals are successful in worldly pursuits] now representing the TF version of the original $\mathrm{P}$. This second form of overt $\mathrm{TF}$ is expressed in the formula below:

$$
\mathrm{P}^{\prime} \Rightarrow \mathrm{Q}=(\mathrm{TF}) \mathrm{P} .
$$

As can be noticed, as a form of overt TF, the configuration of (16) is the same as (13), save for the operator linking $\mathrm{P}$ ' to $\mathrm{Q}$, which in the present case indicates a pragmatic relationship based on implicature $(\Rightarrow$ ), rather than a logical one based on entailment $(\supset)$ (cf. Horn 2003; Huang 2007 for a comprehensive account on implicature and entailment). Even here, the axiom in (16) is justified by the fact that the logical conjunction $(\wedge)$ between $\mathrm{P}^{\prime}$ [many [evangelicals] are successful 
careerists in professional and business life] and -Q [such evangelicals are not successful in worldly pursuits] would lead $(\vdash)$ to contradiction or inconsistency $(\perp)$ :

(16) a. $\mathrm{P}^{\prime} \wedge-\mathrm{Q} \vdash \perp$

* [many [evangelicals] are successful careerists in professional and business life] and [such evangelicals are not successful in worldly pursuits].

There is a second form of occurrence I take into account in the following survey, namely what I define as covert (or presuppositional) TF, always occurring in the form of a presupposition assuming Q. In this case, we can formally identify an instance of covert (or presuppositional) TF when $\mathrm{Q}$ is encoded constructionally through presupposition triggers. See below:

(17) $[\ldots]$ the embassy to the continents across the Great Sea has, as it seems, your approval.' [...] 'You don't think you might have consulted me before you suggested it?

BNC G17 747

P: $\quad$ the Great Sea has, as it seems, your approval.

P': $\quad$ you don't think you might have consulted me before you suggested it?

Q: $\quad$ you suggested it.

Q': $\quad$ the Great Sea has your approval.

From (17) above we can observe that IE proposition P [the Great Sea has, as it seems, your approval] is originally suspended-factual, as the factuality of $\mathrm{P}$ could be defeased by SP/W (i.e. P, yet, I still don't know if this is true). Nonetheless, subsequently, SP/W utters a new proposition P' [you don't think you might have consulted me before you suggested it?] which includes a temporal clause functioning as a presupposition trigger [before you suggested it]. The latter formally presupposes a factual proposition Q [you suggested it] which semantically entails Q' [the Great Sea has your approval] (cf. Capone 2013 on the relationship between presuppositions and propositional attitudes). The phenomenology of covert or presuppositional TF can be expressed with the following formula:

$$
\text { P'>> Q つ Q' = (TF)P. }
$$


To explain, the expression above reads that a new proposition $\mathrm{P}^{\prime}$ formally presupposes ( $>$ ) a second proposition Q. The latter semantically entails $(\supset)$ Q', the meaning of which is equal $(=)$ to the TF version of the originally suspended-factual proposition $\mathrm{P}^{12}$. The ultimate effects of covert TF are then that an originally suspended-factual proposition P [the Great Sea has, as it seems, your approval] is textually turned into a factualized proposition $\mathrm{Q}^{\prime}=(\mathrm{TF}) \mathrm{P}$ [the Great Sea has our approval]. Finally, similar to what I show for overt TF, even in the case of covert TF, the relationship between Q and (TF)P can be obtained either through entailment $(\supset)$ or conversational implicature $(\Rightarrow)$. In the latter case, the phenomenology of covert TF needs to be posited as follows:

$$
\mathrm{P}^{\prime}>>\mathrm{Q} \Rightarrow \mathrm{Q}^{\prime}=(\mathrm{TF}) \mathrm{P} \text {. }
$$

It is time now to answer the third question (c) at the beginning of this section: what type of suspended-factual propositions $\mathrm{P}$ will be analysed in this survey? As it will be already clear from the examples of overt (12-15) and covert (17) TF provided above, this case-study is centered on IE and indirect evidentials, the factuality of which is always suspended. Based on that, I present a corpus-based study of overt and covert TF phenomena occurring after a suspended-factual P, marked by the IE construction apparently.

\subsection{The TF of apparently: a quantitative description}

In the present section I discuss the results of a corpus-based study of overt and covert phenomena of TF deploying the BNC. To do this, I start from the occurrences of a suspended-factual proposition P, marked by the interpersonal evidential (IE) adverbial apparently. To point out, apart from meanings referring to physical manifestness to the sight, all the usages of adverbials such as apparently or as it appears have the same functions of grammaticalized IE or mediative constructions which can alternatively express inferential or hearsay evidentiality (cf. Lazard 1999, 2001; Tantucci 2013).

\footnotetext{
${ }^{12}$ It may be argued that the relationship between Q and Q' here is based on implicature rather than entailment. While this depends on the criteria according to which textual entailment may be defined (this is not a priority in this paper), this does not constitute a problem for the present analysis, as covert TF may occur either as the result of entailment or implicatures. In fact, depending on the criteria that different scholars may adopt, some cases of TF may be said to be triggered by implicatures, others by presupposition and so forth (i.e. see Simons 2013 on conversational implicatures often generated through presuppositional strategies). That being said, however the the underlying typology of TF-types may be defined, this will not affect the focus nor the quantitative results of this work.
} 
The analysis includes two surveys: one is based on the written register, the other on spoken data. The aim of this study is to find some empirical confirmation of SP/W's frequent inclination towards factuality throughout a text or an ongoing discourse. Crucially, if a proposition P is first introduced in a text as a suspended-factual (marked by apparently), it should be logically inconsistent to have it subsequently reformulated as a new factual proposition. In other words, on a logical level, it should be predicted that every IE proposition P remains suspended-factual until the end of the text. On the other hand, one of the assumptions of this work is that human mind is naturally inclined to exert epistemic control towards a new proposition P (i.e. Langacker 2008, 2009; Kan et. al 2013; Tantucci 2015b). That is, a conceptualiser is more inclined to determine (or presuppose) whether $\mathrm{P}$ is ultimately true or not, rather than keeping its factuality uncertain.

It is not farfetched to suggest that this phenomenon instantiates epistemically as a form of 'conflict monitoring' and perceptual/informational 'cognitive control' (i.e. Schlaghecken \& Martini 2012; see also Kan et al., 2013). This sort of latent epistemic tension determines, on a large scale, diachronic phenomena of semasiological factualization (cf. Tantucci 2015c). The following analysis moves one step further, as it shows that online phenomena of textual factualization (TF) can also be observed operationally during an on-going speech event. Instances of TF re-configuration are likely to affect the interlocutors' working memory with interference/misinformation effects, viz. qualitative alterations of an event memory (cf. Ayers \& Reder 1998; Paz-Alonso \& Goodman 2008; Frenda et al. 2011; Ecker et al. 2015), as they partially overwrite an original memory trace.

In table 1 below, I give some evidence about the latter in written and spoken BE from the BNC:

\begin{tabular}{lccccc}
\hline & Suspended-factuals & & TF & No-reference & $\begin{array}{c}\text { Not-IE/ } \\
\text { unclear }\end{array}$ \\
\hline & & Overt & Covert & & \\
Written BE & 48 & 28 & 22 & 108 & 4 \\
Spoken BE & 40 & 40 & 47 & 67 & 14
\end{tabular}

Table 1.

$\mathrm{TF}$ in written and monological spoken $\mathrm{BE}$ from the $\mathrm{BNC}$

Table 1 classifies 400 occurrences of apparently from the BNC where a new proposition $\mathrm{P}$ is marked as suspended-factual. Under the label Written BE and Spoken BE are respectively 200 
tokens corresponding to a random sample from each genre of the BNC. A sample of 100 tokens is normally considered representative for the quantitative description of a specific token in a corpus (cf. Hoffman et al. 2008: 54; Nelson et al. 2002: 77 on corpus sampling and representativity). Nonetheless, as the present study is focused on the dynamic unfolding of TF throughout a text, a larger sampling data set has been opted for (200 random cases have been qualitatively annotated in both the written and the spoken section of the BNC).

The columns in table 1 correspond to four categories: Suspended factuals (SF), TF, Noreference and Not-IE/unclear. The column Suspended-factuals shows all the cases where a new IE proposition $\mathrm{P}$, marked by apparently, maintained its original suspended-factual meaning throughout the text, and thus was not textually factualized. Conversely, the column TF indicates all the texts where an original suspended-factual P, marked by apparently, was turned subsequently into either an overt or a covert TF proposition. The third column is named No-reference and indicates all the texts where a new proposition $\mathrm{P}$, marked by apparently, was no longer discussed or referred to throughout the text. In this case, a distance of 20 sentences - formally ending with a full stop - was used as a standard measure of judgment. Finally, the last column shows cases where apparently either did not convey an IE meaning (as in the case of physical appearance, i.e. He was looking in her direction, apparently ignoring Bessie, BNC EA5 1703) or was uttered in spoken contexts where the recording was unclear. The results of this survey can be visualized in Figure 5 below:

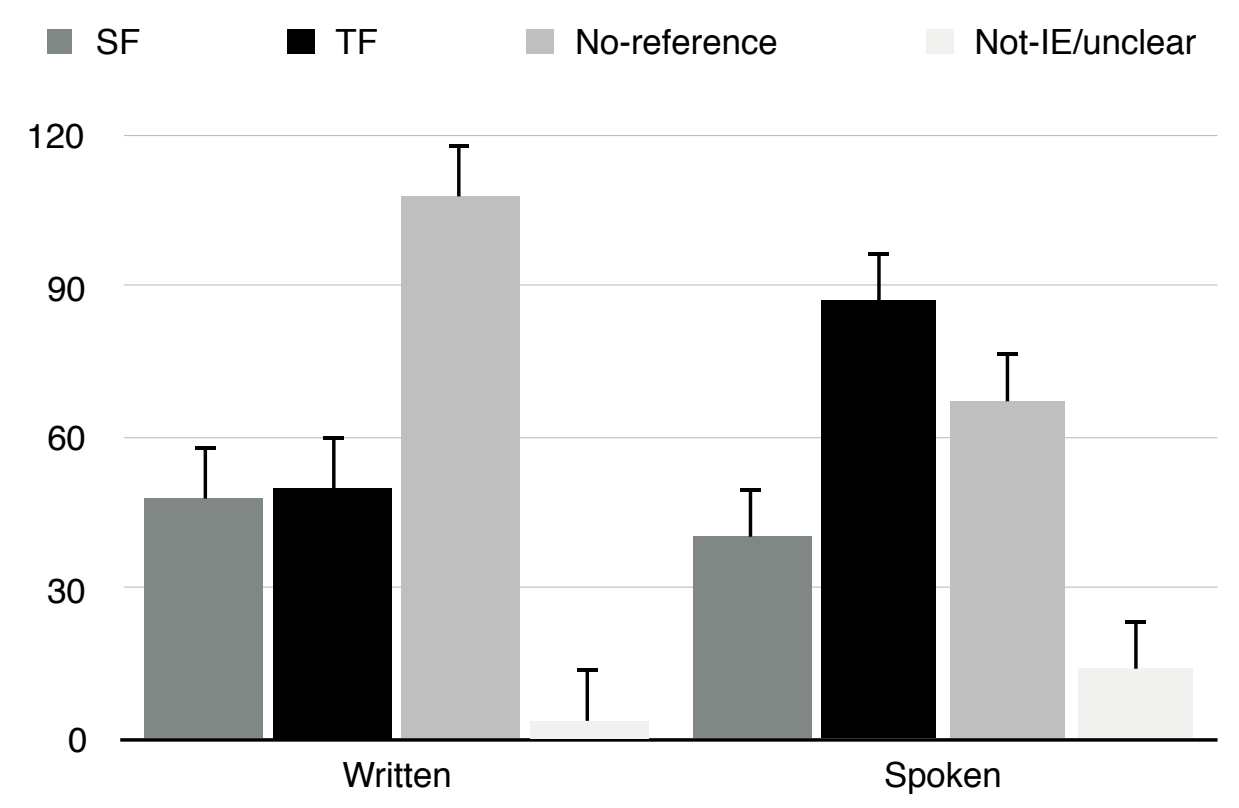

Figure 5.

$\mathrm{TF}$ in written and monological spoken $\mathrm{BE}$ from the BNC 
In the graph above the y axis indicates the raw frequency of all the occurrences under enquiry, while the $\mathrm{x}$ axis refers to the two registers of written and monological spoken BE. Still relying on data provided in table 1, the graph includes 4 columns per each register: IE, TF, No-reference and NotIE/unclear. The black column TF includes both instances of overt and covert factualization.

We can first observe that the black column, referring to TF, occupies a considerable portion of the dataset both in written BE (50) and especially in spoken BE (87). These numbers are most relevant if considered with respect to all the texts where a proposition $\mathrm{P}$, marked by apparently, was actually referred to in a subsequent stage of the speech-event. In this sense, we can dispose of a specific indicator of the role of epistemic inclination toward factuality in TF phenomena throughout an on-going discourse. In other words, based on the present dataset, the question to answer is the following:

When a SP/W refers back to a previously uttered proposition [apparently P] in a text, how often does TF formally occur?

To address this question, we need to exclude from our discussion two of the columns from figure 5 above: No-reference and Not-IE/unclear. The former cannot tell us much about the relationship between epistemic inclination and TF as it corresponds to all the cases where an IE proposition P is no more referred to in a text. The latter is equally not significant as it has to do with non-evidential usages of apparently and with utterances where the recording was unclear.

At this point, we are finally in the position to answer our question, as we can look at the number of $\mathrm{TF}$ with respect to the sum of $(\mathrm{TF}+\mathrm{SF})$ in both registers, as it shown in table 2 below:

\begin{tabular}{lcccc}
\hline & SF & & TF & Total \\
\hline & & Overt & Covert & \\
Written BE & 48 & 28 & 22 & 98 \\
Spoken BE & 40 & 40 & 47 & 128
\end{tabular}

Table 2.

TF vs. SF in written and spoken BE from the BNC

From table 2, we can observe that epistemic inclination seems to constitute a powerful trigger of TF in both written and spoken monological texts. In fact, we can note TF phenomena occurring in 
$51.02 \%(50 / 98)$ of the times a proposition [apparently $\mathrm{P}$ ] is referred back in a written text, and $67.96 \%(87 / 128)$ of the times a proposition [apparently $\mathrm{P}$ ] is referred back in a spoken text. If we consider both written and spoken registers, we can note an average of $60.61 \%$ for a proposition [apparently $\mathrm{P}$ ] to undergo $\mathrm{TF}$ throughout a text (still on the condition that $\mathrm{SP} / \mathrm{W}$ refers to $\mathrm{P}$ on a later stage of the discourse). These results can bring us to two conclusions:

a. Beyond any expectation of logical consistency, TF is textually compatible with suspendedfactuality and occurs more than $60 \%$ of the times it is referred to after the IE construction [apparently $\mathrm{P}]$ throughout a discourse.

b. TF seems is significantly more likely to occur in spoken registers $(87 / 128)$ than written registers $(50 / 98)(\mathrm{p}<0.5)$.

\subsection{The TF of apparently: a qualitative description}

This section focuses on specific examples from the survey in 4.3. I analyse cases of overt and covert $\mathrm{TF}$, instances where a proposition [apparently $\mathrm{P}$ ] textually remains suspended-factual (SF) and also contexts where a proposition [apparently $\mathrm{P}$ ] is not referred to throughout the rest of the text. I discuss below a general case of the latter, labeled as No-reference in table 1:

(20) They, they have found dangerously high levels of benzene in Glasgow, Edinburgh, and other places, and this benzene apparently it can cause cancer. Now you take your choice, it's either benzene in unleaded petrol or lead in leaded petrol! Also, in today's, er Scotland on Sunday, gathered, they found it not just Edinburgh, but Britain as whole I think.

BNC FX5 625

\footnotetext{
$\mathrm{P}: \quad$ this benzene apparently it can cause cancer.

P': ?
}

(20) above is a clear case where a new suspended-factual proposition P marked by apparently is no more referred to in a text. To explain, a new proposition $\mathrm{P}$ is encoded as a suspended-factual statement: this benzene apparently it can cause cancer. However, in the following two sentences there is no reference whatsoever regarding the possibility that [this benzine can cause cancer] is a 
true fact or not. Here I adopted a standard measure of 20 sentences to determine whether a proposition $\mathrm{P}$ is no more referred to in a text and hence to drop it in the No-reference category in Table 1. As I suggested previously, all the No-reference cases are not relevant for this survey, as in such cases we have no formal indicators as to whether $\mathrm{SP} / \mathrm{W}$ is inclined to believe that $\mathrm{P}$ is a true fact or not.

The next example corresponds to the Suspended-factual category in table 1 and relates to all cases where an IE proposition $\mathrm{P}$ was still referred to as a suspended-factual through a text. Simply put, the SF category includes all the cases where TF did not occur:

(21) Peter Ellis, 27, forced them to lie spreadeagled on the ground, and apparently shouted for them to hand over their money and watches. Police sources said that either they were unable to understand him or simply said 'no'.

BNC AJM 182

P: $\quad$ Peter Ellis, 27, apparently shouted for them to hand over their money and watches.

P': $\quad$ Police sources said that either they were unable to understand him or simply said 'no'.

From example (21) above, we can see how a proposition P, marked as an IE with apparently, textually maintains a suspended-factual meaning in a following proposition P'. Namely, the IE proposition P [Peter Ellis, 27, apparently shouted for them to hand over their money and watches] is referred to with a new reportative evidential proposition P' [Police sources said that either they were unable to understand him or simply said 'no'] still encoding suspended-factuality. In fact, the suspended-factuality of P' is preserved through semantic entailment: P' $\supset$ P, as the (reportedly true) fact that they were unable to understand him, entails the (apparently true) fact that Peter Ellis shouted at them.

We can now finally turn to textual factualization $(\mathrm{TF})$ and see how it occurs with respect to a suspended-factual IE proposition [apparently P]. Consider the case of overt TF below:

(22) [...] even bits of excrement, apparently are very interesting to archaeologists [...] All of this $[\ldots]$ have always traditionally been interesting to archaeologists.

BNC HUN 597 
P: $\quad$ even bits of excrement, apparently are very interesting to archaeologists.

P': $\quad$ All of this have always traditionally been interesting to archaeologists.

Q: $\quad$ even bits of excrement, are very interesting to archaeologists.

Similar to example (12) in section 4.2, we are here dealing with an IE proposition $\mathrm{P}$ [even bits of excrement, apparently are very interesting to archaeologists] which is then subsequently referred to with a new assertive proposition P' [All of this have always traditionally been interesting to archaeologists] semantically entailing Q [even bits of excrement, are very interesting to archaeologists]. This whole process is an instance of overt TF, the phenomenology of which - for the reader's convenience - is expressed again in the formula below (the same given in section 4.2):

$$
\mathrm{P}^{\prime} \supset \mathrm{Q}=(\mathrm{TF}) \mathrm{P}
$$

To clarify once more, (23) states that a new proposition P' entails Q, which is equivalent to the TF version of an originally suspended-factual $\mathrm{P}^{13}$.

We can now focus on a specific case of covert TF:

(24) And the disciples had apparently been unable to help the boy. [...] Why could they not heal the boy?

BNC G5H 143

P: $\quad$ the disciples had apparently been unable to help the boy

P': $\quad$ Why could they not heal the boy?

Q: $\quad$ they could not heal the boy

Q': $\quad$ the disciples had been unable to help the boy

In this case, an IE proposition $\mathrm{P}$ [the disciples had apparently been unable to help the boy] is referred back with a new proposition P' [Why could they not heal the boy?]. The latter is encoded in the form of a direct question, functioning as a presupposition trigger of a factual proposition $\mathrm{Q}$ [they could not heal the boy]. Q semantically entails Q' [the disciples had been unable to help the boy]

\footnotetext{
${ }^{13}$ As I mentioned in 4.2, when the relationship between $\mathrm{P}$ ' and Q is based on conversational implicature the following formula applies: $\mathrm{P}^{\prime} \Rightarrow \mathrm{Q}=(\mathrm{TF}) \mathrm{P}$.
} 
which is the TF version of the originally suspended-factual proposition P. The phenomenology of covert TF is given below (the same formula can be found in section 4.2):

$$
\mathrm{P}^{\prime}>>\mathrm{Q} \supset \mathrm{Q}^{\prime}=(\mathrm{TF}) \mathrm{P} \text {. }
$$

To explain once more, P' presupposes (>>) Q. The latter entails $(\supset)$ Q', which is the TF version of an originally suspended-factual $\mathrm{P}^{14}$.

It is now clear how TF formally occurs with respect to an IE proposition P. At this point, there is one last question that needs to be asked:

\section{Why is TF pragmatically successful?}

I propose that TF pragmatically occurs as a result of intersubjectively expected accommodation (cf. Schwenter and Waltereit 2010) on behalf of $\mathrm{AD} / \mathrm{R}$. Furthermore, I here intend TF as an online speech act bearing a social meaning, based on the E-I awareness of an assumed 3rdP, who could potentially justify or support SP/W's epistemic inclination towards $\mathrm{P}$. This phenomenon is valid both in cases of overt $\mathrm{TF}$ and covert $\mathrm{TF}^{15}$. In fact, $\mathrm{TF}$ is clearly neither logically nor semantically predictable from a suspended-factual statement P. It follows that, on a conceptual level, there must be a further element intervening in the SP/W's subsequent proposition $\mathrm{P}$ ' (according to which, $\mathrm{P}$ is then newly conceived as a true fact). Based on the case-studies of semasiological change discussed in Tantucci $(2015 b)$ - where an I-I construction develops through time a new E-I meaning - I speculate here that TF is the pragmatic result of a similar E-I form of social awareness. This construing process is based on the assumption that 3rdP would potentially confirm the new factuality of P. However, while in cases of semasiological and grammatical change, the semantic structure of E-I constructions can be empirically demonstrated and compared with less reanalysed II constructions, on the other hand, in cases of online TF we do not have an empirical methodology to deconstruct the interlocutors' awareness of 3rdP at our disposal. For this reason, my claim about the E-I construing of TF is indeed a speculation based on attested phenomena of extended intersubjectificatiom.

\footnotetext{
${ }^{14}$ As mentioned in 4.2, when the relationship between Q and Q' is based on conversational implicature the following formula applies: $\mathrm{P}^{\prime}>>\mathrm{Q} \Rightarrow \mathrm{Q}^{\prime}=(\mathrm{TF}) \mathrm{P}$.

${ }^{15}$ Concerning this point, it may be interesting to see if $\mathrm{TF}$ is comparatively more frequent in some specific genres (i.e. politics, press and others).
} 
To conclude, while I maintain that 3rdP is an inherent semantic element of diachronically reanalysed E-I constructions, I also propose here that TF is based on a similar form of social construing, implicitly allowing SP/W to turn P into a new factual proposition.

\section{Conclusion}

This paper proposes a new model to address the dynamic relationship between cognitive control and epistemic certainty. A SP/W's epistemic inclination towards the factuality of a proposition $\mathrm{P}$ is shown to occur formally throughout a text, either in the overt form of the assertive reformulation of an originally suspended-factual $\mathrm{P}$, or in the covert form of a presupposition trigger also turning $\mathrm{P}$ into a new factual. I define this online phenomenon as textual factualization (TF) and I demonstrate it to be surprisingly frequent in contexts where an originally suspended-fatual proposition [apparently $\mathrm{P}]$ is subsequently turned into a factualized proposition both in written and spoken texts. I propose that $\mathrm{TF}$ instantiates as a form of interference/misinformation effect as it triggers the qualitative alteration of an event memory by partially overwriting an original memory trace: from [apparently P] to [apparently P].

\section{References}

Abbott, Barbara. 2000. "Presuppositions as non-assertions." Journal of Pragmatics 32:1419-1437.

Allan, Keith. 2013. "What is Common Ground?" In Perspectives on Linguistic Pragmatics, edited by Alessandro Capone, Franco Lo Piparo and Marco Carapezza, 285-310. Cham: Springer International Publishing.

Atlas, Jay David, and Stephen C Levinson. 1981. "It-clefts, informativeness and logical form: Radical pragmatics (revised standard version)." In Radical pragmatics, edited by P. Cole, 1-62. New York: Academic Press.

Aikhenvald, Alexandra Y. 2004. Evidentiality. Oxford: Oxford University Press.

Ayers, Michael S, and Lynne M Reder. 1998. "A theoretical review of the misinformation effect: Predictions from an activation-based memory model." Psychonomic Bulletin \& Review 5 (1): $1-21$.

Belli, Robert F, D Stephen Lindsay, Maria S Gales, and Thomas T McCarthy. 1994. "Memory impairment and source misattribution in postevent misinformation experiments with short retention intervals." Memory \& Cognition 22 (1):40-54.

Botvinick, Matthew M, Todd S Braver, Deanna M Barch, Cameron S Carter, and Jonathan D Cohen. 2001. "Conflict monitoring and cognitive control." Psychological review 108 (3): 642-652.

Bowers, JM, and DA Bekerian. 1984. "When will postevent information distort eyewitness testimony?" Journal of Applied Psychology 69 (3):466-472.

Capone, Alessandro, 2001. Modal Adverbs and Discourse. ETS, Pisa. 
Capone, Alessandro. 2013. "The pragmatics of pronominal clitics and propositional attitudes." Intercultural Pragmatics 10 (3):459-485.

Chafe, Wallace, and Johanna Nichols, eds. 1986. Evidentiality: The linguistic coding of epistemology. Norwood: Ablex.

Clark, H. H., and S. A. Brennan. 1991. "Grounding in communication." In Perspectives on socially shared cognition, edited by L.B. Resnick, J.M. Levine and S.D. Teasley. Washington: APA Books.

Clark, H. H., and C. R. Marshall. 1981. "Definite reference and mutual knowledge." In Elements of discourse understanding, edited by A. K. Joshi, B. Webber and I. Sag, 10-63. Cambridge: Cambridge University Press.

Clark, H. H., and T. B Carlson. 1982. "Hearers and speech acts." Language 58:332-373.

Cornillie, B. (2009). Evidentiality and epistemic modality: On the close relationship between two different categories. Functions of language, 16(1), 44-62.

Cruse, David Alan. 2006. A glossary of semantics and pragmatics. Edinburgh: Edinburgh University Press

Davies, Mark. 2010. The Corpus of Historical American English: 400 million words, 1810-2009. Available online at http://corpus.byu.edu/coha/.

Delogu, Francesca. 2009. "Presupposition." In Key notions for pragmatics, edited by J. Verschueren and Östman Jan-Ola, 195-207. Amsterdam: John Benjamins.

Diamond, Adele. 2013. "Executive functions." Annual review of psychology 64:135-168.

Domaneschi, Filippo. 2011. "Towards a normative epistemic account of presuppositions." Journal of Pragmatics 43 (15):3822-3831.

Ecker, Ullrich KH, Stephan Lewandowsky, Candy SC Cheung, and Murray T Maybery. 2015. "He did it! She did it! No, she did not! Multiple causal explanations and the continued influence of misinformation." Journal of Memory and Language 85:101-115.

Faller, Martina. 2002. "Semantics and pragmatics of evidentials in Cuzco Quechua."PhD, Stanford University, Standford University.

Fetzer, Anita. 2011. "Pragmatics as a linguistic concept." In Foundations of Pragmatics, edited by W. Bublitz, A. H. Jucker and K. P. Schneider, 23-50. Berlin/Boston: Walter de Gruyter.

Frenda, Steven J, Rebecca M Nichols, and Elizabeth F Loftus. 2011. "Current issues and advances in misinformation research." Current Directions in Psychological Science 20 (1):20-23.

Geurts, Bart. 1999. Presuppositions and Pronouns. Oxford: Elsevier.

Goldman, Alvin I. 2006. Simulating minds: The philosophy, psychology, and neuroscience of mindreading. Oxford: Oxford University Press.

Gratton, Gabriele, Michael GH Coles, and Emanuel Donchin. 1992. "Optimizing the use of information: strategic control of activation of responses." Journal of Experimental Psychology: General 121 (4):480-506.

Grice, Paul. 1975. "Logic and conversation." In Syntax and semantics: Speech acts, edited by P. Cole and J. Morgan, 41-58. New York: New York Academic Press.

Grush, Rick. 2004. "The emulation theory of representation: motor control, imagery, and perception." Behavioral and Brain Sciences 27:377-442.

Hoffmann, Sebastian, Stefan Evert, Nicholas Smith, David Lee, and Ylva Berglund-Prytz. 2008. Corpus linguistics with BNCweb: A practical guide. Vol. 6. Frankfurt: Peter Lang.

Huang, Yan. 2007. Pragmatics. Oxford: Oxford University Press.

Huang, Yan. 2011. "Types of inference: Entailment, presupposition, and implicature." In Foundations of Pragmatics, edited by W. Bublitz, A. H. Jucker and K. P. Schneider, 397421. Berlin/Boston: Walter de Gruyter.

Holmes, Janet. 1984. "Modifying illocutionary force." Journal of Pragmatics 8:345-365. 
Horn, Laurence. 2006. "Implicature." In Handbook of pragmatics, edited by Laurence Horn and Gergory Ward, 3-28. Malden/Oxford/Carlton: Blackwell.

Jary, Mark. 2010. Assertion: Palgrave Macmillan.

Kan, Irene P, Susan Teubner-Rhodes, Anna B Drummey, Lauren Nutile, Lauren Krupa, and Jared M Novick. 2013. "To adapt or not to adapt: The question of domain-general cognitive control." Cognition 129 (3):637-651.

Karttunen, Lauri. 1974. "Presupposition and linguistic context." Theoretical linguistics 1 (1-3): 181-194.

Kecskes, Istvan, and Fenghui Zhang. 2009. "Activating, seeking, and creating common ground: A socio-cognitive approach." Pragmatics \& Cognition 17 (2):331-355.

Kecskes, Istvan, and Fenghui Zhang. 2013. "On the dynamic relations between common ground and presupposition." In Perspectives on linguistic pragmatics, edited by A. Capone, F. Lo Piparo and M. Carapezza, 375-395. Cham: Springer International Publishing.

Koschmann, Timothy, and Curtis D LeBaron. 2003. "Reconsidering Common Ground." ECSCW 2003, Helsinki.

Langacker, Ronald W. 2008. Cognitive grammar: A basic introduction. Oxford: Oxford University Press.

Langacker, Ronald W. 2009. Investigations in cognitive grammar. Vol. 42. Berlin: Walter de Gruyter.

Lazard, G. (1999). Mirativity, evidentiality, mediativity, or other? Linguistic Typology, 3(1), 91109.

Lazard, G. (2001). On the grammaticalization of evidentiality. Journal of Pragmatics, 33, 359-367.

Levinson, Stephen C. 2000. Presumptive meanings: The theory of generalized conversational implicature. Cambridge, MA: MIT Press.

Loftus, Elizabeth F. 2005. "Planting misinformation in the human mind: A 30-year investigation of the malleability of memory." Learning \& Memory 12 (4):361-366.

Loftus, Elizabeth F, David G Miller, and Helen J Burns. 1978. "Semantic integration of verbal information into a visual memory." Journal of experimental psychology: Human learning and memory 4 (1):19-31.

Mayr, Ulrich, Edward Awh, and Paul Laurey. 2003. "Conflict adaptation effects in the absence of executive control." Nature neuroscience 6 (5):450-452.

Miller, Earl K., and Jonathan D. Cohen. 2001. "An integrative theory of prefrontal cortex function." Annual Review of Neuroscience 24 (1):167-202.

Moore, George Edward. 1922. Philosophical studies. Berlin: Routledge \& Kegan Paul.

Narrog, Heiko. 2005. "Modality, mood, and change of modal meanings: A new perspective." Cognitive Linguistics 16 (4):677-731.

Narrog, Heiko. 2009. Modality in Japanese: The layered structure of the clause and hierarchies of functional categories. Vol. 109. Amsterdam: Benjamins.

Nelson, Gerald, Sean Wallis, and Bas Aarts. 2002. Exploring natural language: Working with the British component of the international corpus of English. Amsterdam: Benjamins.

Nichols, Shaun, and Stephen P Stich. 2003. Mindreading: An integrated account of pretence, selfawareness, and understanding other minds: Clarendon Press/Oxford University Press.

Norman, DonaldA, and Tim Shallice. 1986. "Attention to Action." In Consciousness and SelfRegulation, edited by Richard J Davidson, Gary E Schwartz and David Shapiro, 1-18. Springer US.

Norrick, Neal R. 2000. Conversational narrative: Storytelling in everyday talk. Amsterdam: John Benjamins Publishing. 
Nuyts, Jan. 2001. "Subjectivity as an evidential dimension in epistemic modal expressions." Journal of Pragmatics 33:383-400.

Nuyts, Jan. 2012. "Notions of (inter) subjectivity." English Text Construction 5 (1):53-76.

Paz-Alonso, Pedro M, and Gail S Goodman. 2008. "Trauma and memory: Effects of post-event misinformation, retrieval order, and retention interval." Memory 16 (1):58-75.

Piwek, Paul, and Emiel Krahmer. 2000. "Presuppositions in Context: Constructing Bridges." In Formal Aspects of Context, edited by Pierre Bonzon, Marcos Cavalcanti and Rolf Nossum, 85-106. Dordrecht: Springer Netherlands.

Premack, David, and Guy Woodruff. 1978. "Does the chimpanzee have a theory of mind?" Behavioral and brain sciences 1 (04):515-526.

Reich, Wendelin. 2011. "The cooperative nature of communicative acts". Journal of Pragmatics, 43(5), 1349-1365.

Riemer, Nick. 2010. Introducing semantics. Cambridge: Cambridge University Press.

Sbisà, Marina. 2009. "Speech act theory." In Key Notions for Pragmatics. , edited by J. Verschueren and J.-O. Östman, 229-242. Amsterdam/Philadelphia: John Benjamins.

Schlaghecken, Friederike, and Paolo Martini. 2012. "Context, not conflict, drives cognitive control." Journal of experimental psychology: Human perception and performance 38 (2): $705-731$.

Schwenter, Sott A., and Richard Waltereit. 2010. "Presupposition accommodation and language change." In Subjectification, Intersubjectification and grammaticalization, edited by K. Davidse and L. Vandelanotte, 75-102. Berlin: De Gruyter Mouton.

Searle, John R. 1969. Speech acts: An essay in the philosophy of language. Vol. 626. Cambridge: Cambridge University press.

Simons, Mandy, Judith Tonhauser, David Beaver, and Craige Roberts. 2010. "What projects and why." Semantics and linguistic theory, Ithaca, NY.

Stalnaker, Robert C. 1974. "Pragmatic presuppositions." In Semantics and Philosophy, edited by M. K. Munitz and P. K. Unger, 197-214. New York: New York University Press.

Stalnaker, Robert. 1999. Context and content: Essays on intentionality in speech and thought. Oxford: Oxford University Press.

Stalnaker, Robert. 2002. "Common ground." Linguistics and philosophy 25 (5):701-721.

Strawson, Peter F. 1973. "Austin and 'locutionary meaning'." In Essays on JL Austin, edited by Berlin et al., 46-68. Oxford: Clarendon Press.

Tantucci, Vittorio. 2013. "Interpersonal evidentiality: The Mandarin V-过 guo construction and other evidential systems beyond the "source of information'." Journal of Pragmatics 57:210-230.

Tantucci, Vittorio. 2015a. "Traversativity and grammaticalization: The aktionsart of 过 guo as a lexical source of evidentiality." Chinese Language and Discourse 6 (1):57-100.

Tantucci, Vittorio. 2015b. "Epistemic inclination and factualization: a synchronic and diachronic study on the semantic gradience of factuality." Language and Cognition 7 (3):371-414.

Tantucci, Vittorio. 2015c. "From immediate to extended intersubjectification: A gradient approach to intersubjective awareness and semasiological change." Language and Cognition FirstView:1-33. doi: doi:10.1017/langcog.2015.26.

Tantucci, Vittorio. In press. "Towards a typology of constative speech acts: Actions beyond evidentiality, epistemic modality and factuality." Intercultural Pragmatics 13 (2).

Tomasello, Michael. 2009. The cultural origins of human cognition: Harvard University Press.

Tonhauser, Judith. 2012. "Diagnosing (not-) at-issue content." Proceedings of Semantics of Underrepresented Languages of the Americas (SULA) 6:239-254. 
Traugott, Elizabeth C. 2010. "Revisiting subjectification and intersubjectification." In

Subjectification, Intersubjectification and grammaticalization, edited by K. Davidse and L. Vandelanotte, 29-70. Berlin: De Gruyter Mouton.

Traugott, Elizabeth C. 2012. "Intersubjectification and clause periphery." English Text Construction 5 (1):7-28.

Ullsperger, Markus, Lauren M Bylsma, and Matthew M Botvinick. 2005. "The conflict adaptation effect: It's not just priming." Cognitive, Affective, \& Behavioral Neuroscience 5 (4):467472.

Van der Sandt, Rob A. 1992. "Presupposition projection as anaphora resolution." Journal of semantics 9 (4):333-377.

Von Heusinger, Klaus. 2013. "The Salience Theory of Definiteness." In Perspectives on Linguistic Pragmatics, edited by A. Capone, Lo Piparo F. and Carapezza M., 349-374. Berlin: Springer.

Verhagen, Arie. 2005. Constructions of Intersubjectivity: Discourse, syntax and cognition. Oxford: Oxford University Press.

Willett, Thomas. 1988. "A cross-linguistic survey of grammaticization of evidentiality." Studies in Language 12 (1):57-91. 